\title{
Yield efficiency for apple trees depending on intensive orchard systems in the Kabardino- Balkarian Republic
}

\author{
Abdulabek Rasulov ${ }^{1}$, Beslan Beslaneev ${ }^{1,}{ }^{*}$, Muchazir Kalmykov ${ }^{1}$, and Akrom Ishnazarov ${ }^{2}$ \\ ${ }^{1}$ Kabardino-Balkarian State Agricultural University named after V.M. Kokov, Lenin Avenue, 1V, \\ 360030 Nalchik, Russia \\ ${ }^{2}$ Tashkent State University of Economics, Islam Karimov Str., 49, 100066 Tashkent, Republic of \\ Uzbekistan
}

\begin{abstract}
The study investigated effects of intensive orchard density of different apple cultivars on the yield on the M9 and NK stocks, in comparison with planting on the MM106 stock with the same spindleshaped crown pruning in the foothills of the KBR. In the first 3 variants, the orchard is on espalier and on drip irrigation, in the 4th and 5th variants - without espalier, irrigated along the furrows. With a non-spaller system and without drip irrigation, the average yield of the Idared, Golden Delicious, Prikubanskoye varieties was 35-37 t/ha, and in the espalier orchid on a M9 dwarf rootstock and on drip irrigation with a planting density of 3170 trees/ha the average yield of the Golden Bee, Granny Smith and Gala varieties was at around $40-43 \mathrm{t} / \mathrm{ha}$. With a superdense planting of Jonagold and Golden Bee trees varieties (6660 trees/ha), the average yield was 66.2-68.7 t/ha. The production of a high-density orchard of the Red Delicious Sandidge variety planted in 2012 with a planting scheme $3,5 \times 0,5 \mathrm{~m}(5700$ trees/ha) was $30 \mathrm{t} / \mathrm{ha}$ in the $3 \mathrm{rd}$ year, $50 \mathrm{t} / \mathrm{ha}$ in the 4 th year, and $55 \mathrm{t} / \mathrm{ha}$ in the 5 th year.
\end{abstract}

\section{Introduction}

The innovative development of horticulture and greenhouse vegetable production by introducing modern European technologies, which have greatly progressed over the past two to three decades has recently become one of the main directions of development of the agro-industrial complex of the Kabardino-Balkarian Republic.

"Since the last decade of the 20th century, a new impetus was given to the horticulture development in the world, as a result of a new technology developed in Holland and based on a number of innovative methods, such as increasing the density of planting dwarf apple trees up to 3 thousand trees per 1 ha, the use of crowned seedlings with formed fruit buds at planting, the use of drip irrigation, foliar spray of trees with fertilizers containing not only the main nutrients $\mathrm{N}, \mathrm{P}, \mathrm{K}, \mathrm{Ca}, \mathrm{Mg}$, but also microelements and a number of other innovations"[1-4]. "Such orchards enter the fruiting period already in the 2nd year after

*Corresponding author: beslaneev@mail.ru 
planting and promptly giving a yield of up to $10-15 \mathrm{t} / \mathrm{ha}$, and in the 4 th- 5 th year the yield reaches 40-50 t/ha" [11]. "The implementation of this technology allowed China to increase its apple production in 15 years from 5-6 million tons to 25 million tons per year. The other countries have succeeded in reducing the total area of orchards by 2-3 times, while remaining the total production of fruits at the same amount" [1-2].

In Russia, the implementation of the new technology into horticulture started 15-20 years later than in Europe, with the exception of Sad Gigant JSC in the Krasnodar Territory $[1,5]$. In the Kabardino-Balkarian Republic, the first superintensive orchards on European technology began to be planted in 2009-2010, in other republics of the North Caucasus 5-6 years later [6]. The North Caucasus has the most favorable natural and climatic conditions for the development of intensive horticulture on European technology. The same planting systems, technological methods, varieties as in European countries are used here.

In recent years, in the Kabardino-Balkarian Republic, orchards of two types are predominantly planted: a superintensive orchard of dwarf trees on an M9 stock on espalier and on drip irrigation with a planting density of 3 thousand or more trees per 1 ha, and the second type is an intensive orchard of semi-dwarf trees on MM106 and NK2 stocks without espalier and drip irrigation with a planting density of 850 - 1000 trees per 1 ha.

"Areas of new plantings in Kabardino-Balkaria for the period 2010-2019 amounted to approximately 10 thousand hectares, the ratio of orchards of the first and second types is approximately equal. The total area of orchards in the republic is 20 thousand hectares, by 2025 the production of fruits will reach 500 thousand tons (in 2020 they reached 330 thousand tons). The capacity of fruit storages is 150 thousand tons. The choice of these types of orchards is also related to the fact that since 2015 the state has been subsidizing $80 \%$ of all costs for planting orchards with a density of more than 800 trees per 1 ha" $[6,7]$.

It should be noted that in the North Caucasus there are still not enough fruit tree nurseries to grow seedlings with a branched crown, which are necessary for the planting of superintensive orchards, so the seedlings have to be imported from the European Union countries. Predominantly farmers cultivate planting material according to the old technology, that is, producing of one-year-old trees without side branches, which are used for planting orchards of the second type.

The cultivation features of seedlings of a new type are the following. It is necessary to use free from viruses stocks and cuttings for scions [12]; in the production of one-year-old seedlings with formed crown (having side branches), the technology provides for a decrease in planting density from 50 to 30-35 thousand stocks per 1 ha; to carry out high budding and meticulous care (irrigation, fertilization); to carry out 2-fold treatment of plant tops using a manual spray bottle of the Arbolin (a mixture of Gibberellin A3 with benzylaminopurine or benzyladenine) during the period of the most active growth of grafted trees (June) [3], in order to temporarily suspend the apical growth and, thereby, stimulate the awakening to the growth of lateral shoots. Manual nipping of apical leaflets also gives some awakening of lateral buds, however, there is no simultaneous fruit buds setting, that means the acceleration of tree flowering is not observed $[7,8]$.

In addition to one-year-old seedlings with lateral branches (with formed crown with fruit buds), it is possible to cultivate the same seedlings from winter grafting plantings. Winter graft trees in the first year usually reach a height of $100-120 \mathrm{~cm}$, that means they do not reach the 1st grade standard, so they are left for the 2 nd year. According to the new technology, before the beginning of the second growing season, they are cut off at a level of $60 \mathrm{~cm}$, the growing lateral shoots are removed, leaving only the uppermost one, and when its height reaches about $60 \mathrm{~cm}$, the top is sprayed with Arbolin to stimulate the rise of side branches and the setting of fruit buds. Arbolin (Promolin) is not registered in our country; its replacement, Applin, has recently appeared, but its effectiveness on seedlings has not yet been studied. 
The advantage of such orchards is an early entry into fruiting (in the 2nd year after planting), a significant reduction in the share of manual labor in the most laborious processes, pruning and harvesting. The advantage is also reflected in obtaining highly competitive products, not worse than foreign ones on quality [1-3]. Such orchards can recoup investment by the age of 4 , and this is 2-3 times earlier than traditional orchards on medium-sized stocks $[3,5]$.

So what are the differences between an orchard laid out on Eurotechnology and an orchard laid out on the old technology? The main difference is the quality of the planting material. Foreign planting material is grafted on an M9 dwarf stock, it is free from viruses, quite high - up to $170-180 \mathrm{~cm}$, the body diameter is $17-18 \mathrm{~mm}$, in the zone of the $1 \mathrm{st}$ tier on the trunk there are about 7-10 lateral branches (at a height of 60 to $100 \mathrm{~cm}$ ). Grafting (or budding) is carried out at a height of $25-30 \mathrm{~cm}$ above the root collar. This increases the influence of the dwarf stock on the growth of the aboveground part of the fruit tree.

In turn, the trees are planted so that the grafting site is about $15 \mathrm{~cm}$ above the soil surface. After planting, the branches and the main brunch are cut slightly - by $15-20 \mathrm{~cm}$, i.e. preserve the entire aerial part of the tree. The planting scheme is usually $3.5 \times 0.9 \mathrm{~m}(3170$ trees/ha). Such an orchard just after planting looks like a 3-year-old, due to a significant number of overgrowing branches and twiglets of different lengths.

Planting is carried out not very deep, trees can bend and fall, so an espalier is needed to immediately tie tree trunks to it. The sometimes installed temporary espalier is made of wooden stakes, to which a double twine is pulled, and it is unreliable in a rainstorm with a squally wind. It is advisable to install an espalier made of reinforced concrete posts and several rows of wire before planting an orchard. The height of the support should be $4.5 \mathrm{~m}$, given that an anti-hail net is being pulled over the tree crowns (the production of poles and nets is already being carried out in the KBR).

Shallow planting of trees and the absence of post-planting pruning of seedlings made it necessary to constant irrigation of trees. For this purpose, primarily a sprayer tank with two hoses, irrigating two rows at once is used. Later on, drip irrigation is set up as soon as possible.

The formation of the trees crown in the orchard is carried out according to the "slender spindle" type, which means the presence of a central trunk and numerous lateral branches that have a horizontal position. The diameter of the crown in the lower part is up to 1.0-1.1 $\mathrm{m}$, in the middle part is $0.7-0.8 \mathrm{~m}$, in the upper part is $0.3-0.4 \mathrm{~m}$, in this zone, the presence of long branches is not allowed [2].

In the summer months (July - August) of the first year after planting, it is important to deflect branches longer than $40 \mathrm{~cm}$ to a horizontal position and tie them up. In winter or early spring, all branches with acute angles of discharge that could not be rejected during the growing season are removed. At the same time a thorn of about $1 \mathrm{~cm}$ is left, when cutting out the branches and the cut is left horizontal so that the shoot that appears later from the hemp appeared from below, and not from above, and had a horizontal position.

In the 2nd and 3rd vegetation, similar summer operations are carried out. In winter, together with competitors, branches with the thickness of $2 / 3$ of the main brunch are removed; the main brunch should be noticeably thicker than the side branches and dominate over them.

In addition to the works described above, on trees at the age of 4 and more years in the winter, regular thinning of the crown is carried out, $1 / 3$ of the longest and most fertile branches are removed, ensuring that all 3-4-year-old fertile branches are gradually replaced in 3 years.

The soil between the rows is kept according to the lawn system, which is gradually formed from natural grass in 2-3 years with 3-4-fold annual mowing of growing grasses 
with a frontal Italian mower. The near-stem strips are kept clean, treated with herbicides (Roundup and its analogues) twice per vegetation.

Mineral supplements (fertilizers) in tinned soil conditions are more efficient to apply together with irrigation (fertigation). Foliar feeding is also carried out on the leaves with chemicals containing fertilizers with macro and microelements (Aquarin, Ravstorin, etc.).

The latest highly effective chemicals are used as means of protection against diseases and pests. Spraying them is usually carried out at least every 7-10 days, and in case of heavy rainfall, treatments are carried out even more often. The total number of treatments of the orchard with means of protection reaches 20 or more per season.

The purpose of our work is to monitor the growth and fruiting of new intensive orchards in the Kabardino-Balkaria conditions, as well as to identify the key features of the technology of this orchard type, which provide the targeted harvest.

In the process of fruit production intensification, according to the financial resources of commodity producers, various systems and types of apple tree orchards are created. In countries with developed horticulture, agricultural producers have completely switched to a high-intensive orchard type with a planting density of 3-3.5 thousand low-growing trees per 1 ha on a dwarf M9 stock with a yield of about $50 \mathrm{t} / \mathrm{ha}[1,2,7,8]$. There are similar orchards in Kabardino-Balkaria on an area of up to 10 thousand ha. Due to the current economic situation, medium-intensive orchards with the placement of about 850-1000 semi-dwarf trees per 1 ha on NK2, MM106 and M26 stocks, with a targeted yield of about 30-35 t/ha are being laid on an equal basis with high-intensive orchards. Unlike the first type orchards, they do not require supporting structures and drip irrigation, greatly reducing the cost of planting and arranging the orchard [6]. In some cases, on a limited area of $0.2-$ 0.3 ha of household farms, super-dense plantings (5500-6500 trees per 1 ha) are laid on the M9 stock, with espalier and drip irrigation [11].

\section{Materials and Methods}

Observations and registrations were carried out according to generally accepted methods [10].

The impact of the planting density on the yield on the M9 stock (3170 pieces); 5700 and 6660 trees per 1 ha, 2500 trees on the SK4 stock, was investigated in comparison with planting on the MM106 stock, 870 trees per 1 ha in the conditions of the foothills of the KBR. Crown formation in all plantings is spindle-shaped. In the first 3 variants, the orchard is on an espailer and on drip irrigation, and in the 4th and 5th variants - without an espailer, irrigated along the furrows. Different varieties of apple trees were studied.

The purpose of the research was to give a comparative assessment of the orchard productivity in plantings of different types, as well as to determine the indicators of biological productivity to characterize the production process.

Plantings of apple trees are of different planting densities (scheme and year of planting, stock, studied varieties are presented in the table). The orchards are located in the foothill area on land owned by peasant farm enterprises, located in the suburb of Nalchik. The soils are leached chernozeums with an average supply of basic nutrients. In the years under review, the temperature and humidity conditions were within the normal range, the average annual temperature was $9.3^{\circ} \mathrm{C}$, precipitation was $600-630 \mathrm{~mm}$ per year.

Plantations on MM106 and NK4 stocks are cultivated without support and drip irrigation, but irrigation is carried out during dry periods by overflow (on MM106) or with a hose (on NK4). In these orchards were used domestic seedlings without branching.

Espalier and drip irrigation are installed in the plantations on the M9 stock. Seedings with branching on the M9 stock were brought from Italy. In all plantings, the crown is spindle-shaped, the tree height is $3.0 \mathrm{~m}$, with the exception of the most dense planting, 
where the height of the trees reaches 3.5-3.8 m. A high agricultural background, which is necessary for a modern intensive orchards has been achieved in orchard plantings.

\section{Results and Discussion}

From the information presented in the table, it can be seen that the yield of the orchard differs significantly depending on the type of planting.

When comparing two orchards cultivated on a unsupported structure (the first two variants), it can be seen that the Idared variety in an orchard with 870 trees (MM106 stock) has a yield of $4.9 \mathrm{t} / \mathrm{ha}$, or $12.3 \%$ more. The average difference for the two varieties is only $2.8 \mathrm{t} / \mathrm{ha}$ and is within the experimental error. Consequently, both types of orchards have the same productivity in the range of 37-35 t/ha and can be estimated as similar. As indicated in the table, orchards on espalier and drip irrigation (3rd variant) with 3 thousand trees per 1 ha, which is most widely used, in general, has a higher yield in the range of 43.0-47.0 t/ha.

There is definitely a fluctuation in yields from year to year in all orchards, which requires more careful setting of standards (removal of excess sets) in years with abundant fruit setting, which is not always carried out basing on the estimated yield [7].

The highest yield was recorded in the orchard with superdense planting $(1.5 \times 1.0 \mathrm{~m})$ 66.2-68.7 $\mathrm{t} / \mathrm{ha}$, which is $26.6 \mathrm{t} / \mathrm{ha}$, or $39.4 \%$ more than the third variant. Given this experience, such type of planting with 6.0-6.5 thousand trees per 1 ha has the right to life and is used in agricultural households. However, the rows must be increased to $2.0 \mathrm{~m}$ (with a planting scheme $2.0 \times 0.7-0.8 \mathrm{~m}$ ), it is recommended to use varieties with moderate growth (Gala, Red Delicious Sandidge, etc.), although ordinary highly productive varieties (such as Golden Delicious, etc.) have shown themselves quite well.

In order to reduce the cost of purchasing seedlings, it is recommended to plant stocks in a permanent place and carry out budding at the location of the future orchard. A gasoline engine mounted on a trolley is used for spraying trees in narrow raws. A vertical spray boom with fittings from a tractor sprayer is also welded onto the base of the trolley.

Table 1. The productivity of orchards depending on the stock, planting system and tree planting density.

\begin{tabular}{|c|c|c|c|c|c|}
\hline \multirow{2}{*}{$\begin{array}{c}\text { Tree } \\
\text { planting } \\
\text { scheme, } \\
\text { stock }\end{array}$} & \multirow{2}{*}{$\begin{array}{c}\text { Trees amount, } \\
\text { thousand per } 1 \\
\text { ha }\end{array}$} & \multirow[b]{2}{*}{ Apple tree variety } & \multicolumn{3}{|c|}{ Yield by years (t/ha) } \\
\hline & & & 2019 & 2020 & $\begin{array}{l}\text { Ave } \\
\text { rage }\end{array}$ \\
\hline \multicolumn{6}{|c|}{ Orchard system - unsupported } \\
\hline \multirow{2}{*}{$\begin{array}{l}5 \times 2.3 \mathrm{~m} \\
\text { MM106 }\end{array}$} & \multirow{2}{*}{0.87} & Idared & 38.0 & 41.4 & 39.7 \\
\hline & & Golden Delicious & 43.2 & 30.4 & 36.8 \\
\hline \multirow{2}{*}{$4 \times 1 \mathrm{~m}, \mathrm{NK} 4$} & \multirow{2}{*}{2.50} & Idared & 33.2 & 36.4 & 34.8 \\
\hline & & Prikubanskoye & 35.0 & 37.0 & 36.0 \\
\hline \multicolumn{6}{|c|}{ Orchard system - espalier } \\
\hline \multirow{3}{*}{$3.5 \times 0.9$, M9 } & \multirow{3}{*}{3.17} & Golden Bee & 42.5 & 47.0 & 44.8 \\
\hline & & Granny Smith & 40.0 & 46.0 & 43.0 \\
\hline & & Gala & 44.4 & 49.6 & 47.0 \\
\hline $3.5 \times 0.5, \mathrm{M} 9$ & 5.70 & $\begin{array}{l}\text { Red Delicious } \\
\text { Sandidge }\end{array}$ & 55.6 & 50.5 & 53.0 \\
\hline \multirow{2}{*}{$1.5 \times 1.0, \mathrm{M} 9$} & \multirow{2}{*}{6.66} & Golden Bee & 67.4 & 70.0 & 68.7 \\
\hline & & Jonagold & 60.5 & 72.0 & 66.2 \\
\hline \multicolumn{3}{|c|}{$\mathrm{LCD}_{05}$} & 5.0 & 4.2 & 4.6 \\
\hline
\end{tabular}


In an orchard with a low-growing variety Red Delicious Sandij and a planting scheme $3.5 \times 0.5 \mathrm{~m}$ (5700 trees/ha) in an orchard on an espalier and drip irrigation, it was identified that in the 3 rd year the yield of the orchard reaches $30 \mathrm{t} / \mathrm{ha}$, and in 4 th year and further 50 $55 \mathrm{t} / \mathrm{ha}$ (Table 1). In this case to obtain a yield of 50 t/ha it is enough to have 45-50 fruits on a tree. With a distance between trees of $50 \mathrm{~cm}$, it is carried out extensive pruning, all growths longer than $30 \mathrm{~cm}$ are cut on a stump, the tree is column-shaped, spur-type varieties are used.

\section{Conclusions}

Consequently, in the conditions of the Kabardino-Balkaria foothills, unsupported orchards on MM106 stocks (870 trees/ha) and NK4 (2500 trees/ha) with formed spindle-shaped crowns and with the use of productive Idared, Golden Delicious, Prikubanskoye varieties provide an average yield of 35-37 t/ha for two years.

The espalier orchard of the Golden Delicious, Granny Smith and Gala varieties on a dwarf M9 stock and drip irrigation with a planting density of 3170 trees/ha has a yield in the range of $40-43 \mathrm{t} / \mathrm{ha}$.

The productivity of a high-density orchard with 5.7 thousand trees/ha of the Red Delicious Sandidge variety is $30 \mathrm{t} / \mathrm{ha}$ in the $3 \mathrm{rd}$ year, and 50-55 t/ha for the 4 th -5 th years.

The superdense planting of trees (6660 trees/ha) of Jonagold and Golden Bee varieties provides an average yield of 66.2-68.7 t/ha for two years.

All mentioned types of orchards and planting systems are quite effective, have the right to exist and are used depending on the production and economic conditions of farms.

\section{References}

1. V. A. Gudkovskii, A. Klad, Horticulture and Viticulture, 4, 2-6 (2001)

2. I. V. Mukhanin, Modern system for creating and cultivating intensive apple orchards, http://asprus.ru

3. I. V. Mukhanin, L. V. Grigorieva, A highly profitable intensive orchard with a "compa ct spindle" formation, http://asprus.ru

4. A. N. Fisenko, E. A. Egorov, V. P. Popova, Weak Gardening, 1, 60-64 (1999)

5. A. A. Solomakhin, Gardening and Nursery, http://asprus.ru

6. A. R. Rasulov, A. K. Ezaov, T. H. Pshikhachev, Z. M. Shakhmurzov, Cultivation of Intensive Apple Orchards in Kabardino-Balkaria (Recommendations) (2012)

7. A. R. Rasulov, A. S. Sarbashev, A. H. Balov, Problems of the development of the agroindustrial complex of the region, 1, 101-104 (2019)

8. V. A. Alferov, Optimization of technological and economic parameters of the structure of agrocoenosis and regulations for the cultivation of fruit crops and grapes, 237-242

9. P. V. Kondratenko, A. M. Silaev, V. V. Torop, Horticulture and Viticulture, 3, 14-16 (2008)

10. Program and methodology for the variety study of fruit, berry and nut crops (1999)

11. A. R. Rasulov, M. M. Kalmykov, B. B. Beslaneev, Collection of scientific works based on the results of the VIII International Scientific and Practical Conference dedicated to the memory of Honored Scientist of the Russian Federation and KBR, Professor B.Kh. Zherukov, 80-83 (2020) 
12. A. R. Rasulov, B. B. Beslaneev Priority directions of innovative development of agriculture: Materials of the All-Russian Scientific and Practical Conference, 60-63 (2020) 